\title{
ON EXTENSIONS AND REFINEMENTS OF HERMITE-HADAMARD INEQUALITIES FOR CONVEX FUNCTIONS
}

\author{
LIANGCHENG WANG
}

Abstract. In this paper, we obtain two theorems: Theorem 1 is extensions and infinite refinements of Hermite-Hadamard inequalities; Theorem 2 is extensions from Theorem 1.

Mathematics subject classification (2000): 26D15.

Key words and phrases: Hermite-Hadamard inequalities, convex function, extension, refinement.

\section{REFERENCES}

[1] G. S. YANG AND K. L. TSENG, On certain integral inequalities related to Hermite-Hadamard inequalities, J. Math. Anal. Appl. 239 (1999), 180-187.

[2] C. L. WANG AND X. H. WANG, On an extention of Hadamard inequalities for convex functions, Chin. Ann. of Math. 3 No. 5 (1982), 567-569.

[3] C. H. Feng, On Hadamard inequalities for convex functions, Chin. Ann. of Math. 6A No. 4 (1985), 443-446. (Chinese)

[4] J. L. BRENNER AND H. ALZER, Integral inequalities for concave functions with applications to special functions, Proc. Roy. Soc. Edinburgh Sect. A 118 (1991), 137-192.

[5] S. S. Dragomir, Two mappings in connection to Hadamard's inequalities, J. Math. Anal. Appl. 167 (1992), 49-56.

[6] G. S. YAng AND M. C. Hong, A note on Hadamard's inequality, Tamkang J. Math. 28, No. 1 (1997), 33-37.

[7] G. S. YANG AND K. L. TsEnG, Inequalities of Hadamard's type for Lipschitzian mappings, J. Math. Anal. Appl. 260 (2001), 230-238.

[8] G. H. Hardy, J. E. Littlewood And G. Pòlya, Inequalities, 2nd ed., Cambridge Univ. Press, Cambridge, 1952.

[9] L. C. WANG, Convex functions and their inequalities, Sichuan Univ. Press, Sichuan, China, 2001. (Chinese) 